TITLE:

\title{
High-precision machining by measurement and compensation of motion error
}

\section{$\operatorname{AUTHOR}(\mathrm{S})$ :}

Kono, Daisuke; Matsubara, Atsushi; Yamaji, Iwao; Fujita, Tomoya

\section{CITATION:}

Kono, Daisuke ... [et al]. High-precision machining by measurement and compensation of motion error. International Journal of Machine Tools and Manufacture 2008, 48(10): 11031110

ISSUE DATE:

2008-08

URL:

http://hdl.handle.net/2433/89646

\section{RIGHT:}

Copyright @ 2008 Elsevier; この論文は出版社版でありません。引用の 際には出版社版をご確認ご利用ください。; This is not the published version. Please cite only the published version. 
High-precision Machining by Measurement and Compensation of Motion Error

\author{
Daisuke Kono $^{1}$, Atsushi Matsubara ${ }^{1}$, Iwao Yamaji, ${ }^{1}$ Tomoya Fujita ${ }^{1}$, \\ ${ }^{1}$ Dept. of Micro Engineering, Graduate School of Engineering, Kyoto University \\ Yoshida-honmachi, Sakyo-ku, Kyoto 606-8501, Japan \\ Email: Daisuke.Kono@t02.mbox.media.kyoto-u.ac.jp \\ Phone: $+81-75-753-5226$ \\ Fax: $+81-75-753-5226$
}

\begin{abstract}
:
This paper describes a systematic method to model and compensate geometric errors of machine tools. In order to separate geometric errors from other errors, measured errors are analyzed in the frequency domain by using the Fourier series. Then, the frequency components corresponding to geometric errors are selected based on the repeatability of their wavelength. Finally, the components are reconstructed and forwarded for the compensation by a fine motion drive. A CNC machine tool with a fine motion mechanism on the Z-axis was developed to compensate the error components in the $\mathrm{Z}$ direction on the XY plane. A flat surface machining with non-rotational cutting tools was tested to validate our approach. On the plane of $45 \mathrm{~mm} \times 70 \mathrm{~mm}$, the fluctuation of the relative displacement was reduced from $1.3 \mu \mathrm{mP}-\mathrm{V}$ to $0.5 \mu \mathrm{mP}-\mathrm{V}$. Machining experiments with a single crystal diamond tool were also carried out and the straightness of the profile curve was reduced from $1.0 \mu \mathrm{m}$ to $0.4 \mu \mathrm{m}$. The result of the experiments showed that the geometric errors were compensated separately from the vibration due to the bending mode of the machine column.
\end{abstract}

Keywords: Compensation, Motion error, High-precision machining, Straightness 


\section{Introduction}

In these days, the demands for high-precision machining with the geometric accuracy and the surface roughness of sub-micrometer level are increasing in the machining areas of optical parts and advanced mechanical parts. It is especially difficult to control the geometric accuracy in the sub-micrometer level, since there exist several errors such as geometric and kinematic errors of machine tools, thermal errors, cutting-force induced errors and other errors [1].

Rectification machining has been used to reduce the geometric errors of the machined parts. In the rectification machining, the geometric errors are measured by using measuring machines after a semi-finishing process. Then, the measured errors are analyzed and forwarded to modify the tool path of a finishing process. Although the rectification machining can compensate repetitive errors, there exist two major problems that affect the accuracy and the efficiency of the machining. One is that the loading and the unloading of the workpiece may significantly increase the lead-time of the manufacturing. The other is the misalignment between measurement and machining coordinates that may worsen the geometric accuracy of the finished surface.

In order to solve those problems, the on-machine measurement [2] has been used. In the on-machine measurement, a scanning probe is attached to the machining head instead of a cutting tool and moved by machine drives [3,4]. However, in this way, geometric errors caused by the machine's motion errors cannot be detected, since the probe's motion itself has the same errors. This is one of traditional issues for metrology researchers, and various error separation techniques such as the reversal method $[5,6]$, the two-point method $[7,8]$ and the three-point method $[9,10]$ have been developed. These methods are quite powerful, but it is time-consuming to reverse the workpiece or to put several probes on the machine between machining processes. Kohno et al. developed an in-process measurement and compensation system of geometric errors for the turning by applying the reversal method $[11,12]$. They showed that this technique was quite practical in cylindrical turning.

Another approach is to separately identify and compensate the geometric errors of the machine and other errors. Yuan et al. developed a motion error compensation system [13]. In their method, the geometric errors of the machine tools are identified and compensated off-line, and then cutting force-induced and thermal-induced errors are estimated and compensated by using error models. The fundamental issue of this approach is the difficulty in accurate identification of geometric errors of the machine, especially when complicated motion errors are caused by mechanical components such as guideways, bearings, and drive-screws are not negligible.

Wei et al. developed an error compensation system for an ultra-precision lathe [14]. 
In this system, the straightness error of the table motion was measured and fedback to a fine tool servo system to compensate it in real-time. Gao et al. and Kim et al. measured axial and angular motion errors of the spindle and the straightness error of Z-axis by using the reference mirror and capacitance sensors for the compensation by a fine tool servo system $[15,16]$. In both methods, measured profiles are assumed to be repetitive and stored in the memories, since complicated geometric errors are induced by the mechanical components. Therefore, time-dependent errors such as the one induced by the table's vibration cannot be separated. These time-dependent errors should be compensated independently.

The objective of our research is to develop a systematic method to model and compensate geometric errors. In order to separate geometric errors from other errors, measured errors are analyzed in the frequency domain by using the Fourier series. Then, the frequency components corresponding to geometric errors are selected based on the repeatability of their wavelength. Finely, the components are reconstructed and forwarded for the compensation by a fine motion drive. In this paper, a flat surface machining with non-rotational cutting tools is tested to validate our approach, as the machined surface directly shows the effectiveness of the compensation.

\section{Modeling and Compensation Method of Motion Error}

\subsection{Motion Error Model}

Figure 1(a) shows a schematic view of surface machining with a non-rotational cutting tool. In this machining, tool motions in the $\mathrm{Z}$ direction are copied on the workpiece. Figure 1(b) shows geometric errors copied on the workpiece according to the tool motion in the $\mathrm{XZ}$ plane. In this machining, the straightness error of the $\mathrm{X}$-axis and the squareness error between the $\mathrm{X}$-axis and the $\mathrm{Z}$-axis cause the machining error. $\mathrm{A}$ motion error composed of these geometric errors is expressed as:

$$
e_{m z}(x)=e_{z}(x)+\beta_{z x} x
$$

where $x$ is the x position of the actual tool position, $e_{m z}(x)$ is the motion error in the $\mathrm{Z}$ direction caused by the tool motion in the $\mathrm{X}$ direction, $e_{z}(x)$ is the straightness error in the $\mathrm{Z}$ direction of the $\mathrm{X}$-axis, $\beta_{z x}$ is the alignment error between the tool motion and the X-axis. The origin of the coordinate is set at the start point of the machining. When the table is driven toward the positive $\mathrm{X}$ direction to obtain the relative motion of the tool to the table, only the first term of Eq.(1) is considered. A motion error is similarly defined in the motion in the YZ plane:

$$
e_{m z}(y)=e_{z}(y)+\alpha_{y z} y
$$

where $y$ is the y position of the actual tool position, $e_{m z}(y)$ is the motion error in the 
$\mathrm{Z}$ direction caused by the tool motion in the $\mathrm{Y}$ direction, $e_{z}(y)$ is the straightness error in the $\mathrm{Z}$ direction of the Y-axis, $\alpha_{y z}$ is the alignment error between the tool motion and the Y-axis. Then, we assume that the motion error in the $\mathrm{Z}$ direction caused by the $\mathrm{XY}$ planar motions, $e_{z}(x, y)$, is expressed as the sum of $e_{m z}(x)$ and $e_{m z}(y)$ :

$$
e_{z}(x, y)=e_{z}(x)+e_{z}(y)+\alpha_{y z} y+\beta_{z x} x
$$

where mutual influences between motions of the X- and Y-axes are ignored.

The alignment errors should be minimized in the assembly of the machine and can be compensated by using the coordinate transformation. In practice, the modeling and the compensation of straightness errors are more difficult. Hence, we focus on the modeling of the straightness errors with measured motion errors to estimate $e_{z}(x, y)$ from Eq.(3).

\subsection{Straightness Error Model}

One of key problems to model the straightness error is the error separation of geometric errors due to the inaccuracy of mechanical components and time-dependent errors such as the one induced by vibrations, since measured motion errors contain both components. In this research, the errors are separated by using the Fourier series. The straightness error is assumed to be composed of a finite number of periodical components. Therefore, the straightness error can be modeled as follows:

$$
e_{z}(x)=\sum_{k=1}^{m} a_{k} \cos \left(2 \pi \cdot \frac{1}{l_{x}} \cdot k\left(x-x_{s t}\right)\right)+b_{k} \sin \left(2 \pi \cdot \frac{1}{l_{x}} \cdot k\left(x-x_{s t}\right)\right)
$$

where $a_{k}$ and $b_{k}$ are the Fourier coefficients, $k$ is the harmonic number, $m$ is the highest order harmonic number of the components to be modeled, $l_{x}$ is the distance of the modeling, $x_{\text {st }}$ is the $\mathrm{x}$ position of the start point of the modeling. Since the modeling error is large near both ends of $l_{x}, l_{x}$ must be set longer than the required distance. The motion error, $e_{z}(y)$, is modeled similarly as $e_{z}(x)$.

The Fourier coefficients and $m$ must be identified from the measured motion errors. More complicated error profiles can be modeled with higher order harmonics. However, higher the order is considered, time-dependent errors affect the model more.

\subsection{Identification of the Error Model and Compensation Algorithm}

Figure 2 shows the algorithm to identify the straightness error model. The identification is independently conducted in each axis. First, the motion error under a certain feedrate is measured several times to compute the average of the errors. The average is defined as $\bar{e}_{z}\left(x_{i}\right), i=1,2, \ldots n_{d}$. The position, $y$, is fixed at a certain position in the compensation area. 
Second, the error is analyzed to identify the model parameters. After the weight is given to $\bar{e}_{z}\left(x_{i}\right)$ to avoid the leakage error, the Fourier transform of $\bar{e}_{z}\left(x_{i}\right)$ is calculated to obtain the power spectrum, $P(\lambda)$, with respect to the wavelength, $\lambda$. The weight of $i$-th sampling point, $f(i)$, is expressed as follows:

$$
f(i)= \begin{cases}-\frac{1}{2} \cos \left(2 \pi \frac{i-1}{2 N}\right)+0.5 & (1 \leq i<N) \\ 1 & \left(N \leq i \leq n_{d}-N\right) \\ -\frac{1}{2} \cos \left(2 \pi \frac{i-n_{d}+N-1}{2 N}-\pi\right)+0.5 & \left(n_{d}-N<i \leq n_{d}\right)\end{cases}
$$

where $N$ is the number of sampling points in the convergence area. To model the error without the distortion, this weight is designed to have the weight of one near the center of the modeling area.

Similarly, the power spectrums calculated from the errors under various federates are computed. The obtained power spectrums are defined as $P_{j}(\lambda), j=1,2 \ldots n_{v}$. Then, the standard deviation and the average of the power spectrums, $\sigma(\lambda)$ and $\bar{P}(\lambda)$, are calculated, respectively. Finally, the shortest $\lambda$ satisfying that $\sigma(\lambda)$ is less than $\sigma_{t}$ and $\bar{P}(\lambda)$ is larger than $P_{t}$ is selected. $\sigma_{t}$ and $P_{t}$ are the tolerance of the standard deviation and the average, respectively. When $\sigma_{t}$ and $P_{t}$ are determined, $m$ is obtained as $m=l_{x} / \lambda$. Figure 3 shows an example of $\sigma(\lambda)$ and $\bar{P}(\lambda)$. In this example, the components with a wavelength of longer than about $4 \mathrm{~mm}$ are modeled under $\sigma_{t}$ of 0.05 and $P_{t}$ of 0.01 .

After the straightness error models are identified, the motion error is estimated from Eq.(3) to compensate it. In this paper, the fine motion drive is used to cancel the estimated motion error.

\section{Compensation Experiment}

The flatness compensation is applied to the motion in a actual machining process, and the variation of the relative displacement of the tool to the table is measured.

\subsection{Machine Tool used in the Experiment}

A machine tool was developed for the experiment. The appearance of the machine is shown in Fig.4. Table 1 shows its major specifications. This machine has three linear axes. A precision ball screw and a servo motor are employed for each drive system. The $\mathrm{X}$-axis employs aerostatic guideways. The $\mathrm{Y}$ - and $\mathrm{Z}$-axes employ linear ball guideways. Since the Y-axis is carefully assembled, $\alpha_{y z}$ is negligible. A commercial CNC controller is used to control these drives. The resolutions of command position trajectories and position feedback signals are one nanometer. This controller employs a 
PI control for the motor current loop, a PI control for the velocity loop and a P control for the position loop.

The Z-axis is equipped with a fine motion mechanism to compensate the motion error. Figure 5 shows the schematic view of the Z-axis and the compensation system. The coarse motion is provided by the ball screw drive system. The fine motion is provided by the piezo electric actuator that changes the preload of the support bearings of the ball screw [17]. A linear encoder with the resolution of $10 \mathrm{~nm}$ is used to detect the position of the Z-axis. A PC, independent of the CNC controllers, controls the fine motion. As for the fine motion drive, the travel is $5 \mu \mathrm{m}$, and the repeatability of the positioning is $0.1 \mu \mathrm{m}$. In order to synchronize the compensation motion in the $\mathrm{Z}$ direction and the position on the XY plane, $x$ and $y$ are measured by using linear encoders with the resolution of $10 \mathrm{~nm}$ and input to the PC through 32bit counter boards.

Figure 6 shows the block diagram for the feedback control of the fine motion. A PI + feedforward controller is selected. When $x$ and $y$ are input to the PC, the estimated error is calculated by the model as a reference. In order to drive motions in both the positive and negative directions, an offset, $d_{\text {off }}$, is added to the reference. The feedforward gain, $K_{f}$, the proportional gain, $K_{p}$, and the integral gain, $K_{i}$, were tuned experimentally. The parameters used in this experiment are $d_{\text {off }}=2 \mu \mathrm{m}$, $K_{f}=0.14, K_{p}=0.14$ and $K_{i}=200$.

\subsection{Experimental Method}

Figure 7 shows the compensation area and the evaluation area of the motion error. First, the motion errors are measured by using an artifact (an optical flat) to identify the parameters of the error model. Figure 8 shows the experimental setup. The optical flat is fixed on the $\mathrm{X}-\mathrm{Y}$ table and a laser displacement sensor is fixed on the Z-axis. The specifications of the measuring instruments are shown in Table 2.

The Y-axis is fixed at the center of the compensation area, and $e_{z}(x)$ is measured by using the laser displacement sensor when the $\mathrm{X}$-axis is driven under the federates of 4800, 7200 and $9600 \mathrm{~mm} / \mathrm{min}$. The $\mathrm{x}$ position is measured by using the linear encoder. The sampling frequency is set to $1 \mathrm{kHz}$. The number of measurements is 3 times. $e_{z}(y)$ is measured similarly as $e_{z}(x)$. In this experiment, error components with a wavelength of longer than $4 \mathrm{~mm}$ are modeled to compensate the mechanical waviness. The number of sampling points in the convergence area, $N$, is set to $10 \%$ of the total number of sampling points.

Then, the relative displacement of the tool to the table are measured under the feedrate of $7200 \mathrm{~mm} / \mathrm{min}$. The pick feed, $P_{f}$, is given toward the positive $\mathrm{X}$ direction, and the Y-axis is driven toward the positive direction to measure the relative 
displacement. The pick feed, $P_{f}$, is set to $1 \mathrm{~mm}$. Measurements with and without the compensation are conducted for comparison.

\subsection{Experimental Result}

Figures 9 and 10 show the relative displacement of the tool without and with the compensation, respectively. The data are filtered with a low pass filter to eliminate the noise of the measurement. The cutoff frequency of the low pass filter is set to $50 \mathrm{~Hz}$.

Comparing Fig. 9 with Fig. 10, the fluctuation of the relative displacement with the compensation is smaller than that without compensation. The periodical fluctuation with the wavelength of $10 \mathrm{~mm}$ is reduced especially on the Y-axis. This wavelength corresponds to the lead of the ball screw. The fluctuations of the relative displacement are about $1.3 \mu \mathrm{mP}-\mathrm{V}$ without the compensation and about $0.5 \mu \mathrm{mP}-\mathrm{V}$ with the compensation.

\section{An Application Example to the Machining}

\subsection{Experimental Method}

The flatness compensation is applied to the surface machining mentioned in Section 2.1. In the experiment, surfaces are machined with and without the compensation, and the profile curves of the machined surface are compared.

Figure 11 shows the experimental setup. The tool is a single crystal diamond tool, and the workpiece material is aluminum. The workpiece is fixed on the table by using a small precision vice, and the tool is fixed on the tool post. The pick feed, $P_{f c}$, is given toward the positive $\mathrm{X}$ direction, and the $\mathrm{Y}$-axis is driven toward the positive direction for the machining. The cutting conditions are shown in Table 3.

The profile curves are measured along the cutting direction by using a surface roughness measuring machine. The number of the measurement points is 50000 points per $10 \mathrm{~mm}(0.2 \mu \mathrm{m} /$ point $)$.

\subsection{Experimental Result}

Figure 12 shows the comparison of the profile curve of the machined surface and the measured relative displacement of the tool without the compensation. Figure 13 shows the comparison of the profile curve and the estimated relative displacement of the tool with the compensation. The estimated relative displacement is calculated by subtracting the command displacement of the compensation motion from the relative displacement shown in Fig. 12. The profile data of the machined surface are calculated by averaging the data of 100 points. The straightness of the profile curve is about 1.0 $\mu \mathrm{m}$ without the compensation and about $0.4 \mu \mathrm{m}$ with the compensation. 
The fluctuation due to the ball screw can be observed in the relative displacement shown in Fig. 12. Its wavelength is $10 \mathrm{~mm}$, and its amplitude is about $1.0 \mu \mathrm{m}$. This fluctuation is copied on the profile curve. The fluctuation with the wavelength of 0.8 $\mathrm{mm}$ and the amplitude of about $0.6 \mu \mathrm{m}$ can be also observed in the relative displacement. The vibration due to the bending mode of the machine column causes this fluctuation. The influence of the vibration to the surface profile is from $0.1 \mu \mathrm{m}$ to 0.2 $\mu \mathrm{m}$.

Comparing the profile curves shown in Fig. 12 and Fig. 13, the geometric error on the surface profile due to the ball screw is similarly reduced as is on the relative displacement profile. However, the geometric error with the wavelength of $0.8 \mathrm{~mm}$ is not reduced. This shows that the geometric errors were compensated separately from time-dependent errors by our compensation method.

\section{Conclusion}

A systematic method to model and compensate geometric errors was developed to improve the flatness of the workpiece. A CNC machine tool with a fine motion mechanism on the Z-axis was developed to conduct compensation experiments. The compensation method was evaluated in both measurement and machining. In this study, the following conclusions were obtained.

(1) The motion errors measured by using an artifact and a laser displacement sensor were analyzed in the frequency domain to separate the geometric errors from time-dependent errors. The geometric error components in the $\mathrm{Z}$ direction caused by the runout of ballscrew drives were selected based on the repeatability of their wavelength and modeled as the Fourier series.

(2) The fine motion mechanism was used to compensate the motion errors. On the plane of $45 \mathrm{~mm} \times 70 \mathrm{~mm}$, the fluctuation of the relative displacement was reduced from $1.3 \mu \mathrm{mP}-\mathrm{V}$ to $0.5 \mu \mathrm{mP}-\mathrm{V}$.

(3) The compensation was applied to surface machining with a non-rotational cutting tool. The geometric errors were compensated separately from the vibration due to the bending mode of the machine column. The straightness of the profile curve was reduced from $1.0 \mu \mathrm{m}$ to $0.4 \mu \mathrm{m}$.

\section{Acknowledgement}

This research is partly supported by JSPS/MEXT Grant-in-Aid for Scientific Research (C) 18560103. The design and fabrication of the experimental device are supported by NSK Ltd., Mitsubishi Electric Corporation, HEIDENHAIN K.K., and 
industria Co, Ltd. Authors would like to give special thanks to these supports.

\section{References}

[1] R. Ramesh, M.A. Mannan, and A.N. Poo: Error compensation in machine tools - a review Part I: geometric, cutting-force induced and fixture-dependent errors, International Journal of Machine Tools \& Manufacture, 40, 2000, 1235

[2] J. Takashita: Machining center with automatic measuring function, Journal of JSPE, 54, 1988, 647.

[3] H. Nakagawa, T. Hirogaki, Y. Kaji, Y. Kita and Y. Kakino: In-situ Suitable Controlled Scan of Laser Stylus for Point Measuring of Free Surface, Journal of JSPE, 69, 2003, 1423.

[4] M. Shiraishi: Scope of in-process measurement, monitoring and control techniques in machining processes-Part 2: In-process techniques for workpieces, Precision Engineering, 11, 1989,27

[5] R.R. Donaldson: A simple method for separating spindle error from test ball roundness error, Annals of the CIRP, 21, 1972, 125

[6] C.J. Evans, R.J. Hocken and W.T. Estler: Self-Calibration: Reversal, Redundancy, Error Separation, and 'Absolute Testing', Annals of the CIRP, 45 ,1996, 617

[7] H. Tanaka, K. Tozawa, H. Sato, M. O-hori and H. Sekiguchi: Application of a new straightness measurement method to large machine tool, Annals of the CIRP, 30, 1981, 455

[8] S. Kiyono and W. Gao: Profile measurement of machined surface with a new differential method, Precision Engineering, 16, 1994, 212

[9] H. Tanaka and H. Sato: Extensive analysis and development of straightness measurement by sequential-two-points method, Trans. ASME Journal of Engineering for Industry, 108, 1986, 176

[10] W. Gao and S. Kiyono: On-Machine Profile Measurement of Machined Surface Using the Combined Three-Point Method, JSME International Journal, C 40, 1997, 253

[11] T. Kohno, Y. Okazaki, N. Ozawa, K. Mitui and M. Omoda: In-process measurement and a workpiece-referred form accuracy control system (WORFAC): concept of the method and preliminary experiment, Precision Engineering, 11, 1989,9

[12] Y. Uda, T. Kohno and T. Yazawa: In-process measurement and workpiece-referred form accuracy control system (WORFAC): application to cylindrical turning using an ordinary lathe, Precision Engineering, 18, 1996, 50 
[13] J. Yuan and J. Ni: The real-time error compensation technique for CNC machining systems, Mechatronics, 8, 1998, 359

[14] G.S. Wei, L.H. Seok, M. Rahman and F. Watt: A fine tool servo system for global position error compensation for a miniature ultra-precision lathe, International Journal of Machine Tools \& Manufacture, 47, 2007, 1302

[15] W.Gao et al.: Measurement and compensation of error motions of a diamond turning machine, Precision Engineering (2006), doi: 10.1016/j.precisioneng. 2006.06.003

[16] J.D.Kim and D.S.Kim: Waviness compensation of precision machining by piezo-electric micro cutting device, International Journal of Machine Tools \& Manufacture, 38, 1998, 1305

[17] N. Tanaka: Development of Nano-Positioner, NSK Technical Journal, 680, 2006, 29 


\section{List of Figure Captions}

Figure 1 Surface machining with a non-rotational cutting tool

Figure 2 Algorithm to identify the straightness error model

Figure 3 An example of the standard deviation and the average of power spectrums

Figure 4 Machine tool used in the measurement

Figure 5 Schematic view of the Z-axis and the compensation system

Figure 6 Block diagram of the controller of the fine motion mechanism

Figure 7 Compensation area and evaluation area of motion errors

Figure 8 Experimental setup

Figure 9 Relative displacement of the tool to the table without the compensation

Figure 10 Relative displacement of the tool to the table with the compensation

Figure 11 Experimental setup

Figure 12 Comparison of the profile curve and the relative displacement of the tool without the compensation

Figure 13 Comparison of the profile curve and the estimated relative displacement of the tool with the compensation 


\section{List of Table Captions}

Table 1 Major specifications of the machine tool

Table 2 Specifications of optical flat and displacement sensor

Table 3 Cutting conditions 


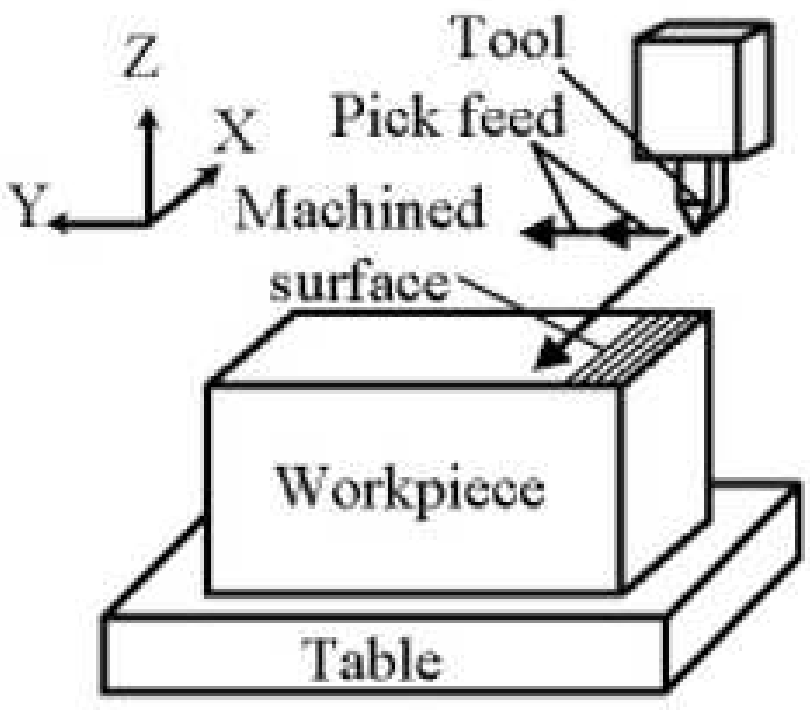

(a) Surface machining

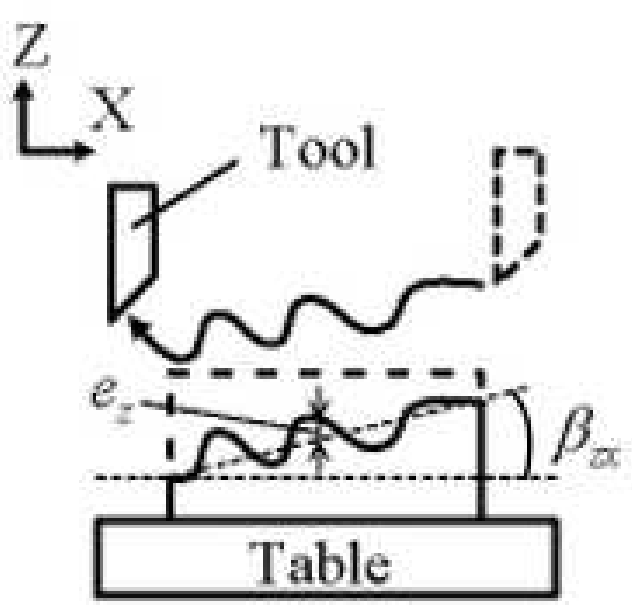

(b) Geometric errors copied on the machined surface 


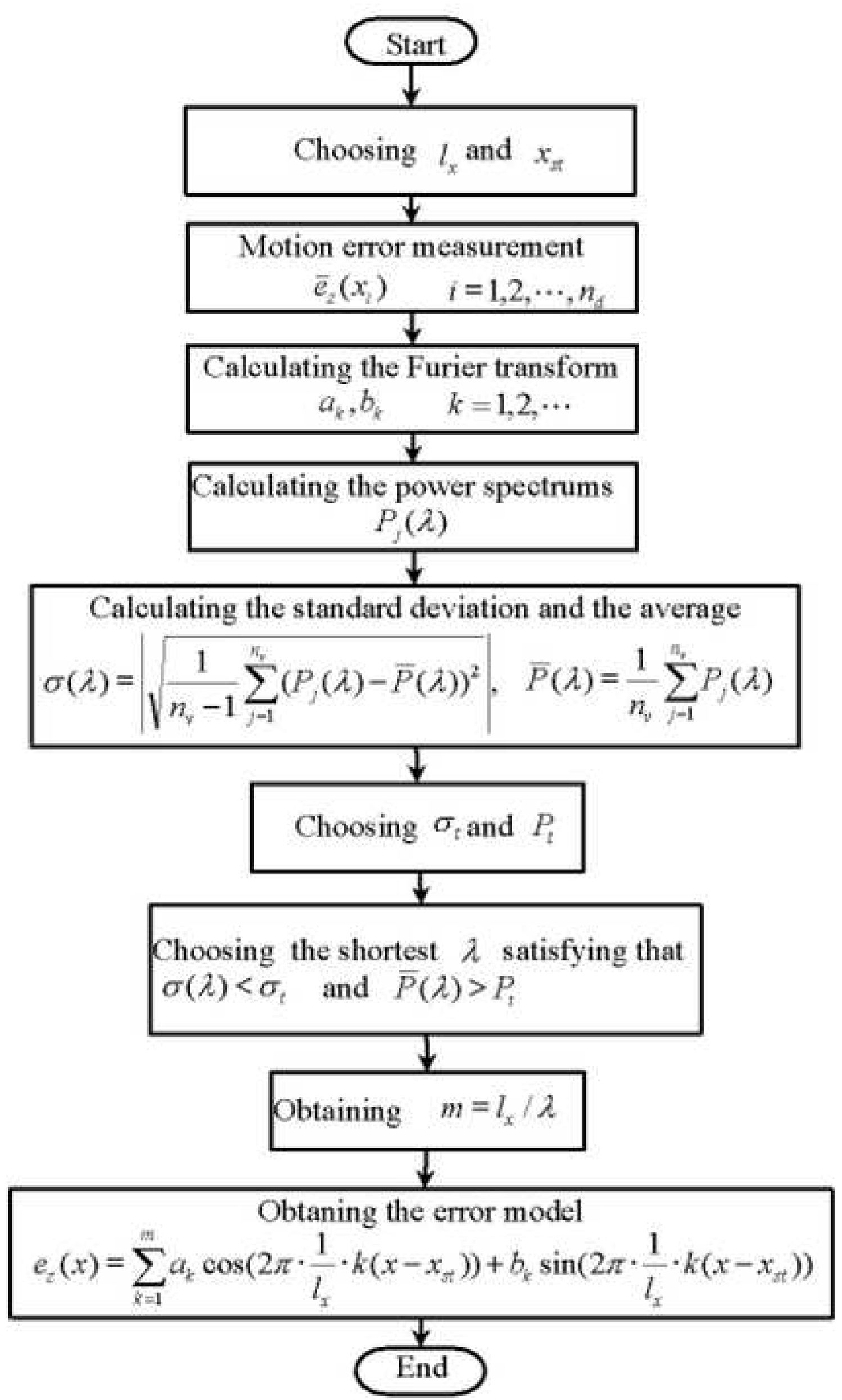

\section{Start}

Choosing $l_{x}$ and $x_{2}$

\section{$\downarrow$}

Motion error measurement

$$
\bar{e}_{z}\left(x_{i}\right) \quad i=1,2, \cdots, n_{f}
$$

$$
\text { F }
$$

$$
a_{k}, b_{k} \quad k=1,2, \cdots
$$

\begin{tabular}{c} 
Calculating the Furier transform \\
$\qquad a_{k}, b_{k} \quad k=1,2, \cdots$ \\
\hline \\
Calculating the power spectrums \\
$P_{j}(\lambda)$
\end{tabular}

$$
P_{j}(\lambda)
$$

Calculating the standard deviation and the average

$$
\sigma(\lambda)=\left|\sqrt{\frac{1}{n_{y}-1} \sum_{j=1}^{n_{j}}\left(P_{j}(\lambda)-\bar{P}(\lambda)\right)^{2}}\right|, \quad \bar{P}(\lambda)=\frac{1}{n_{\nu}} \sum_{j=1}^{n_{j}} P_{j}(\lambda)
$$

\section{Choosing $\sigma_{t}$ and $P_{t}$}

\section{$\downarrow$}

Choosing the shortest $\lambda$ satisfying that $\sigma(\lambda)<\sigma_{t}$ and $\bar{P}(\lambda)>P_{t}$

Obtaining $m=l_{x} / \lambda$

Obtaning the error model

$e_{z}(x)=\sum_{k=1}^{m} a_{k} \cos \left(2 \pi \cdot \frac{1}{l_{x}} \cdot k\left(x-x_{\pi}\right)\right)+b_{k} \sin \left(2 \pi \cdot \frac{1}{l_{x}} \cdot k\left(x-x_{x t}\right)\right)$

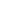
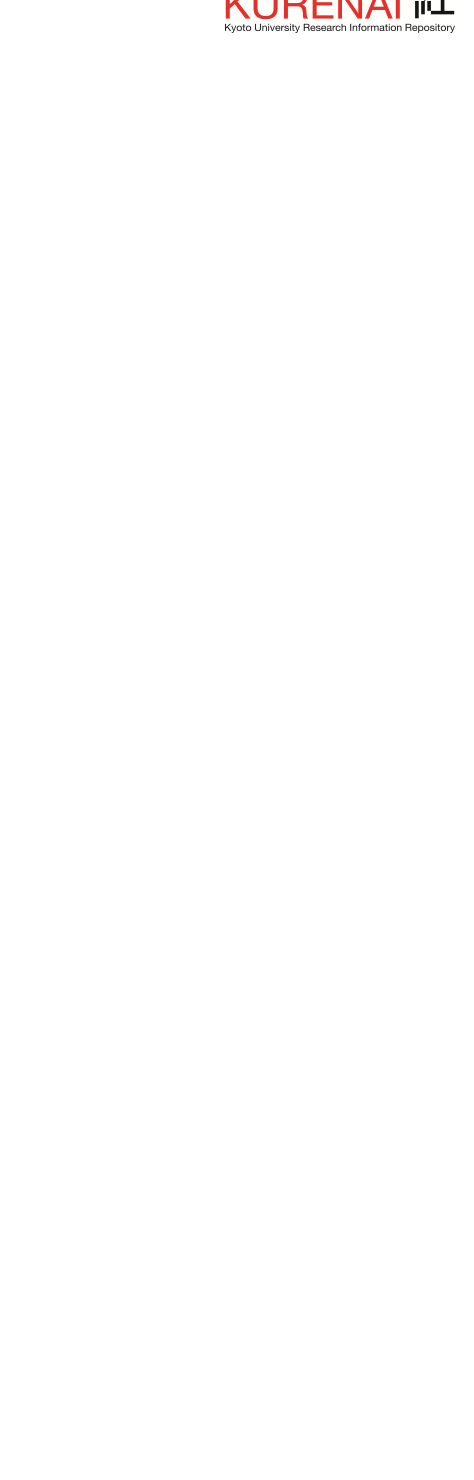


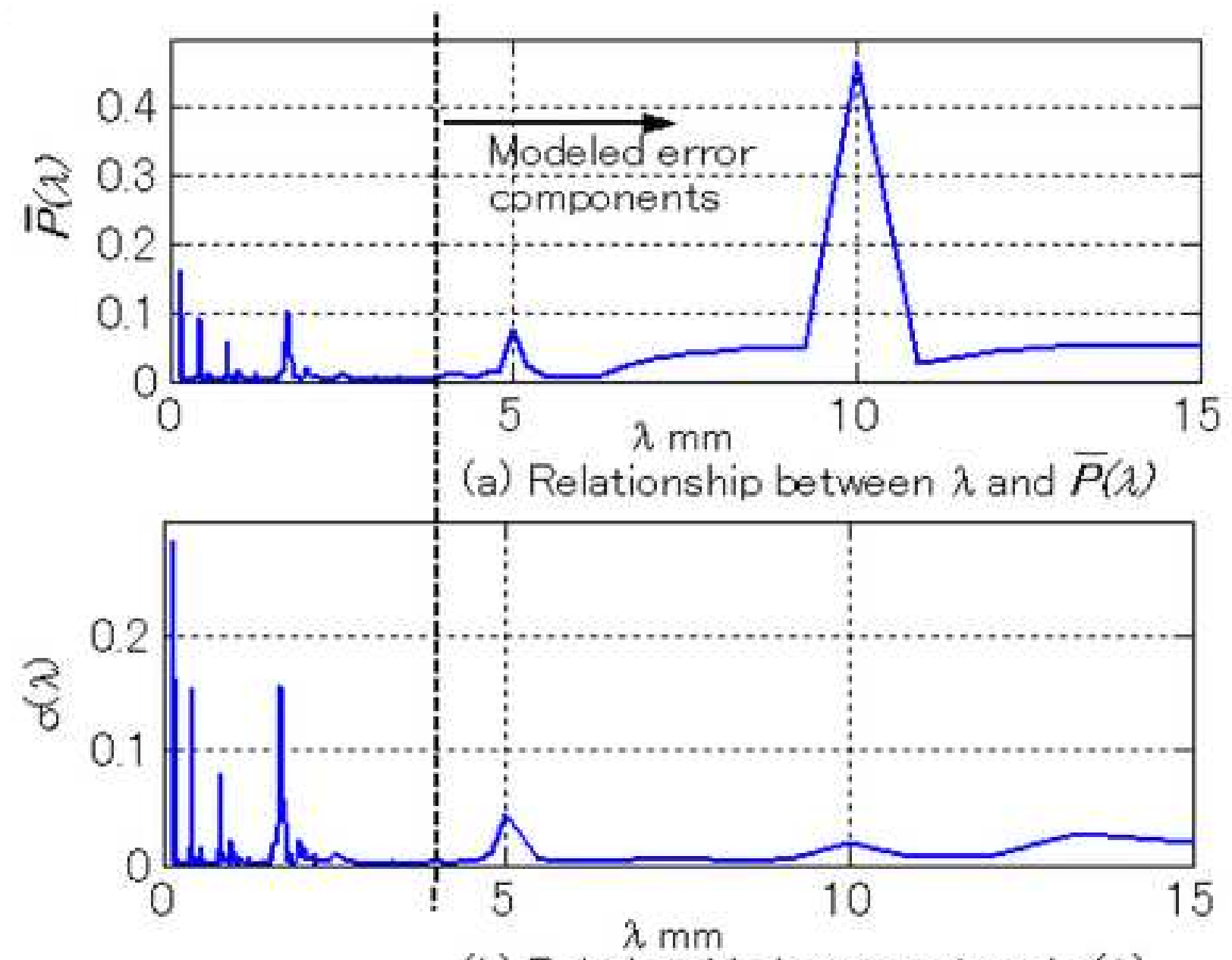

(b) Relationship between $\lambda$ and $\sigma(\lambda)$ 


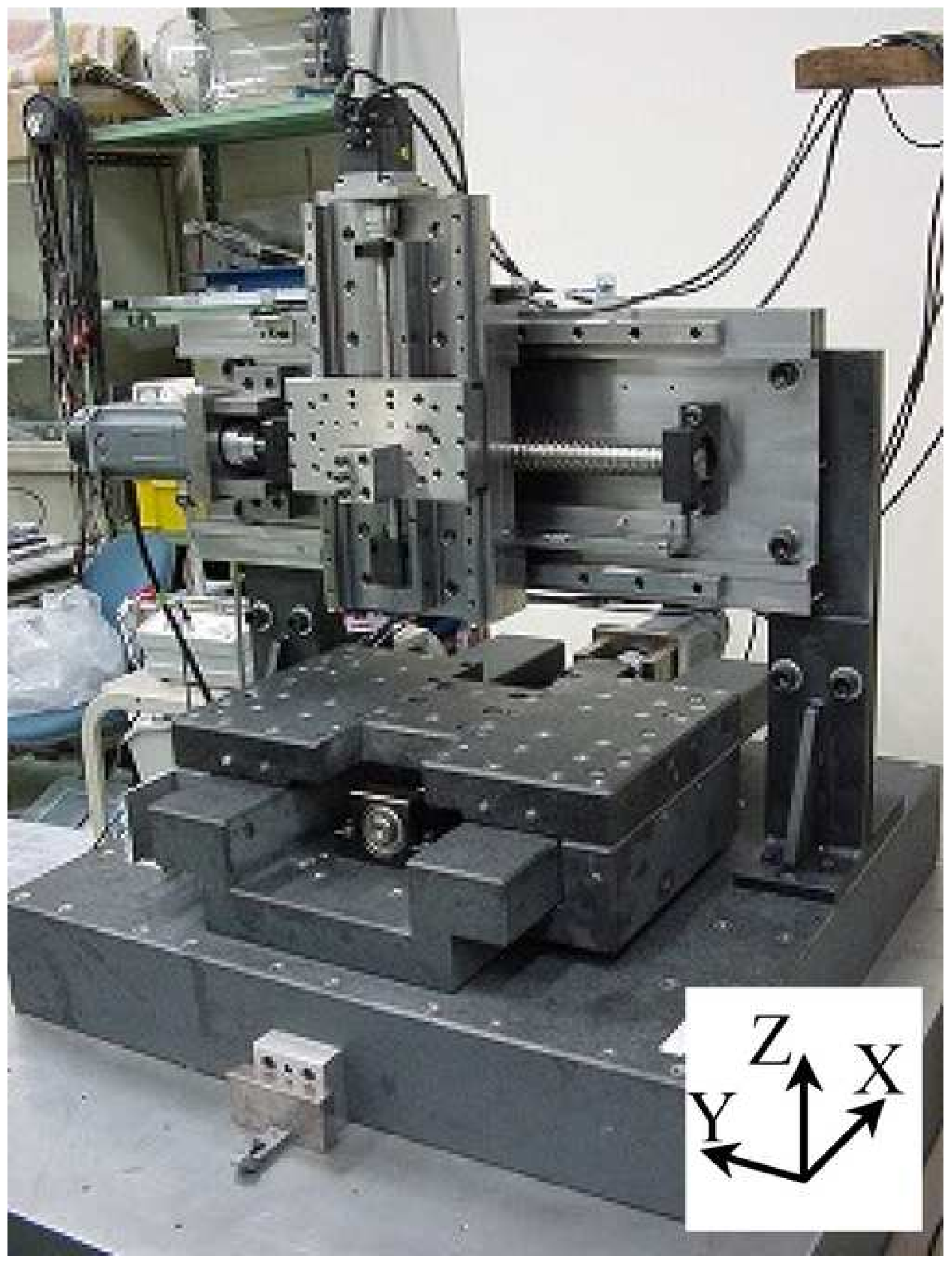




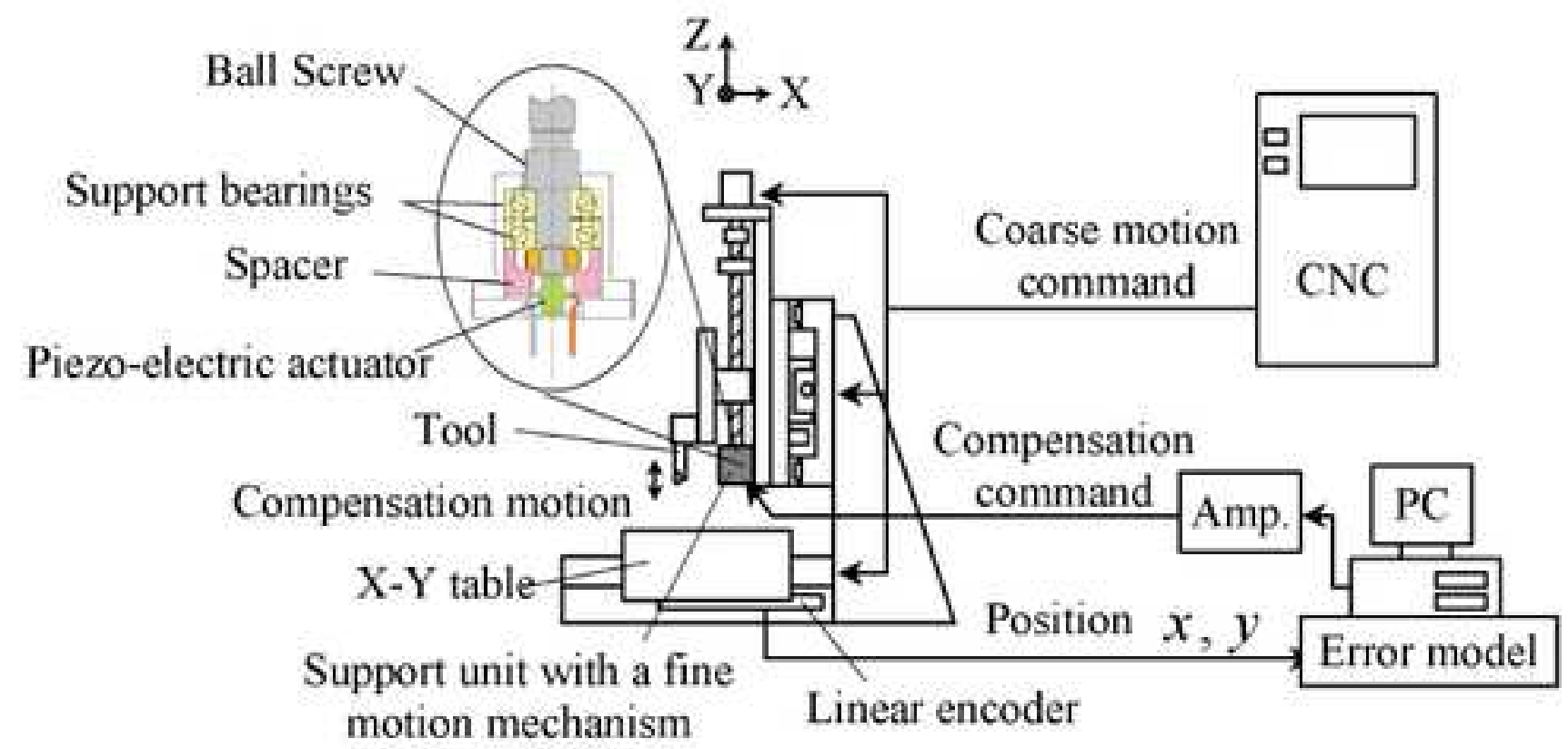




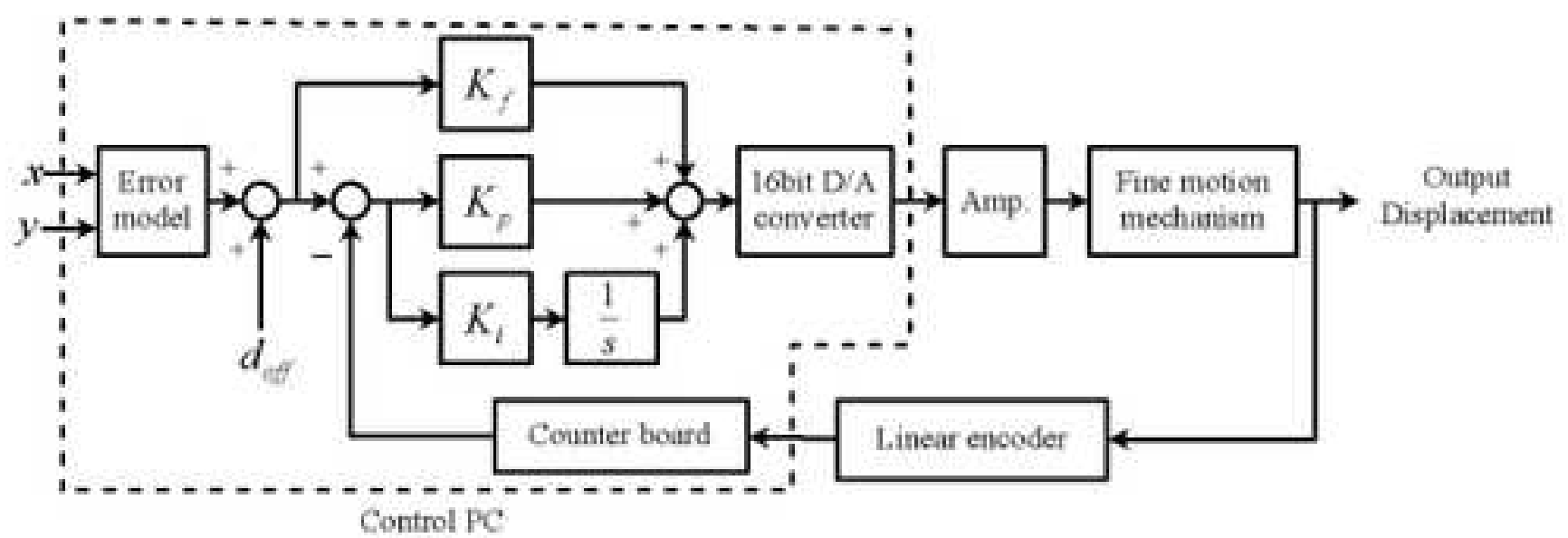




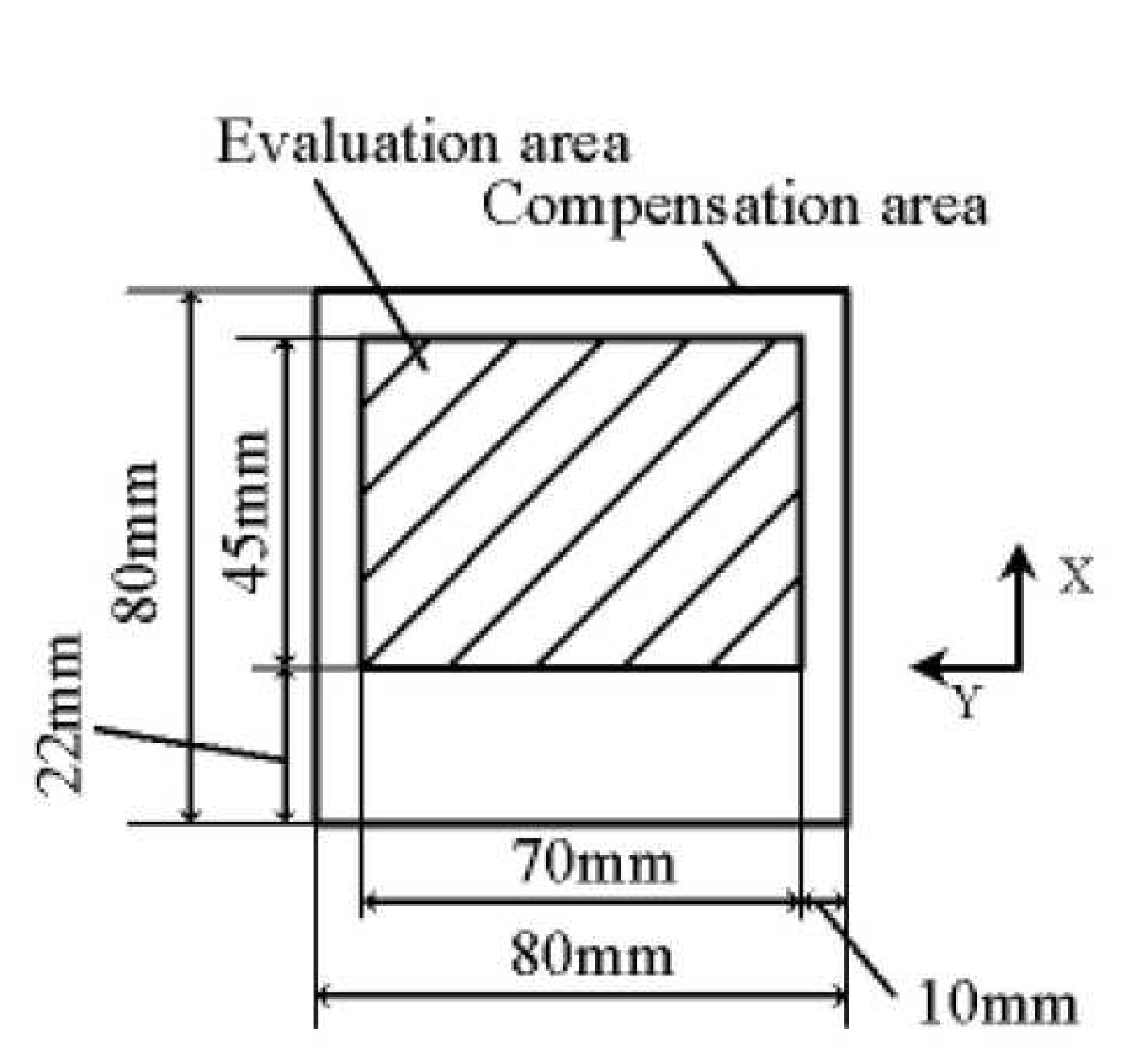

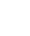

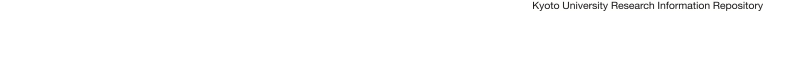

(n)

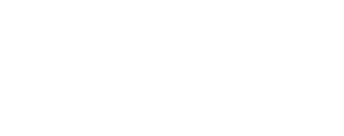

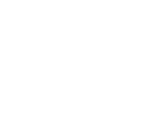

Evaluation area

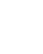

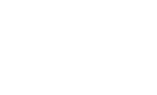

a

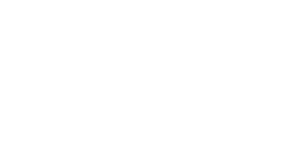




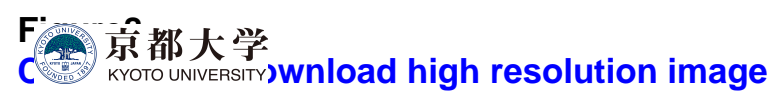

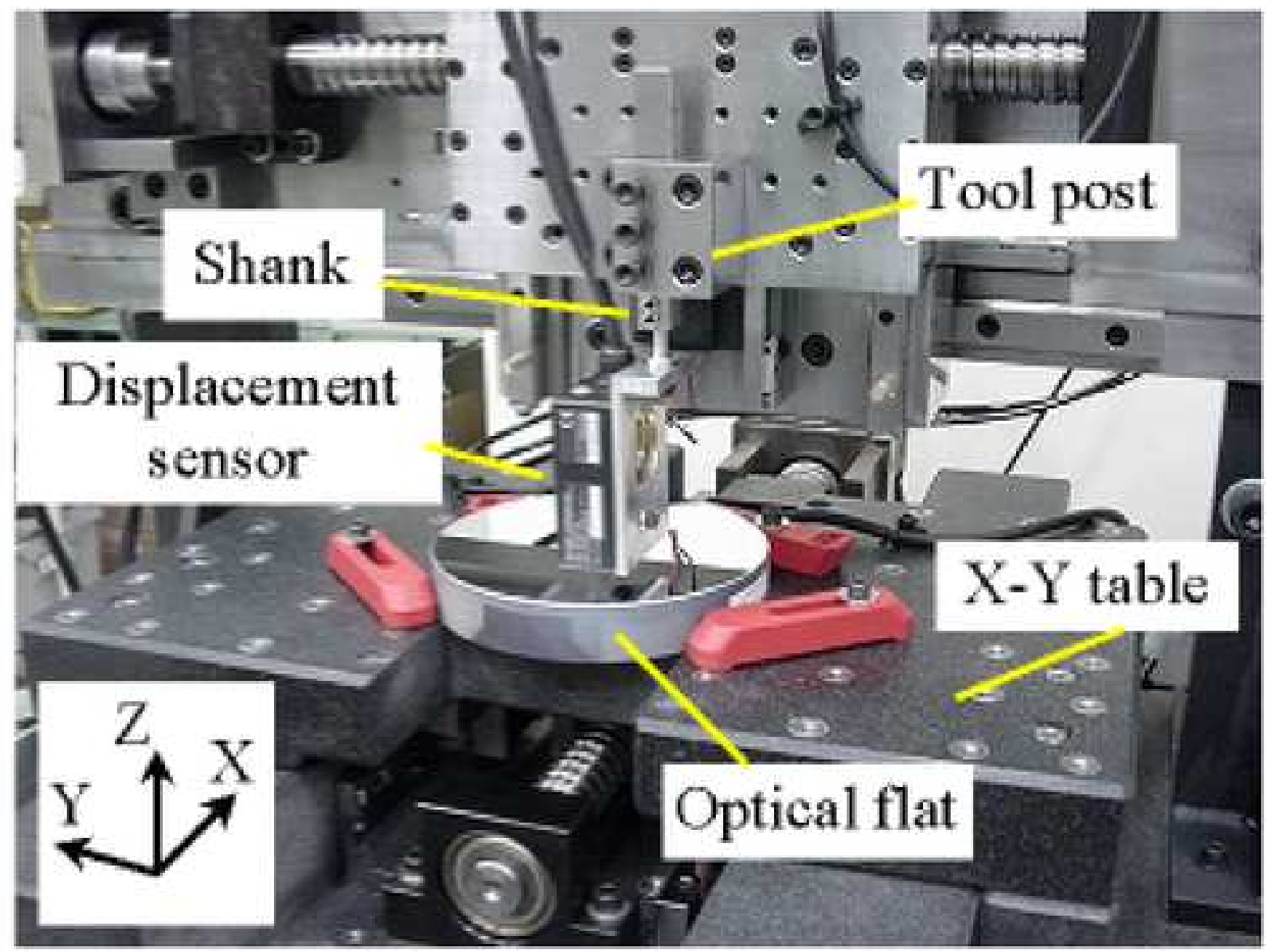




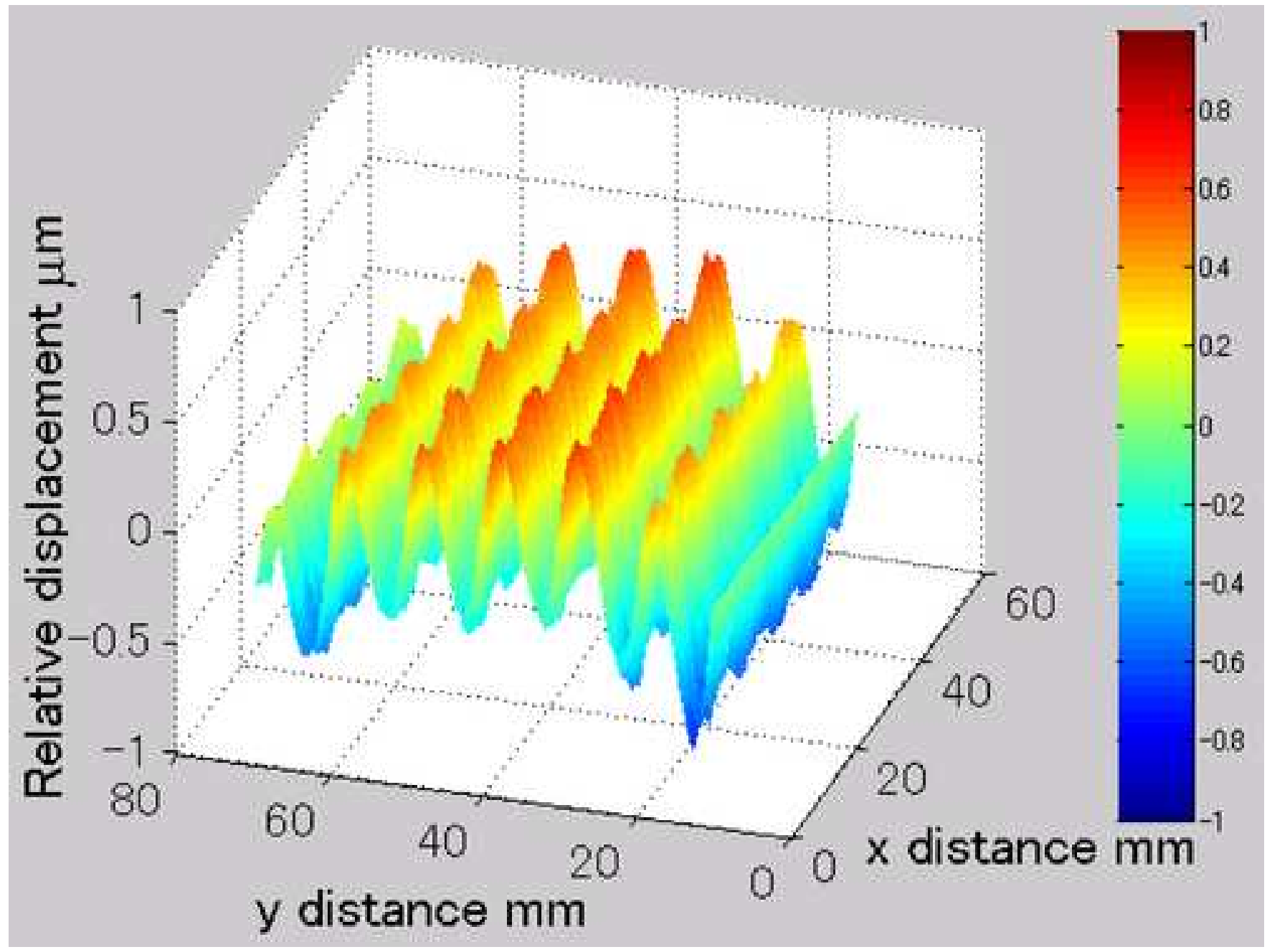




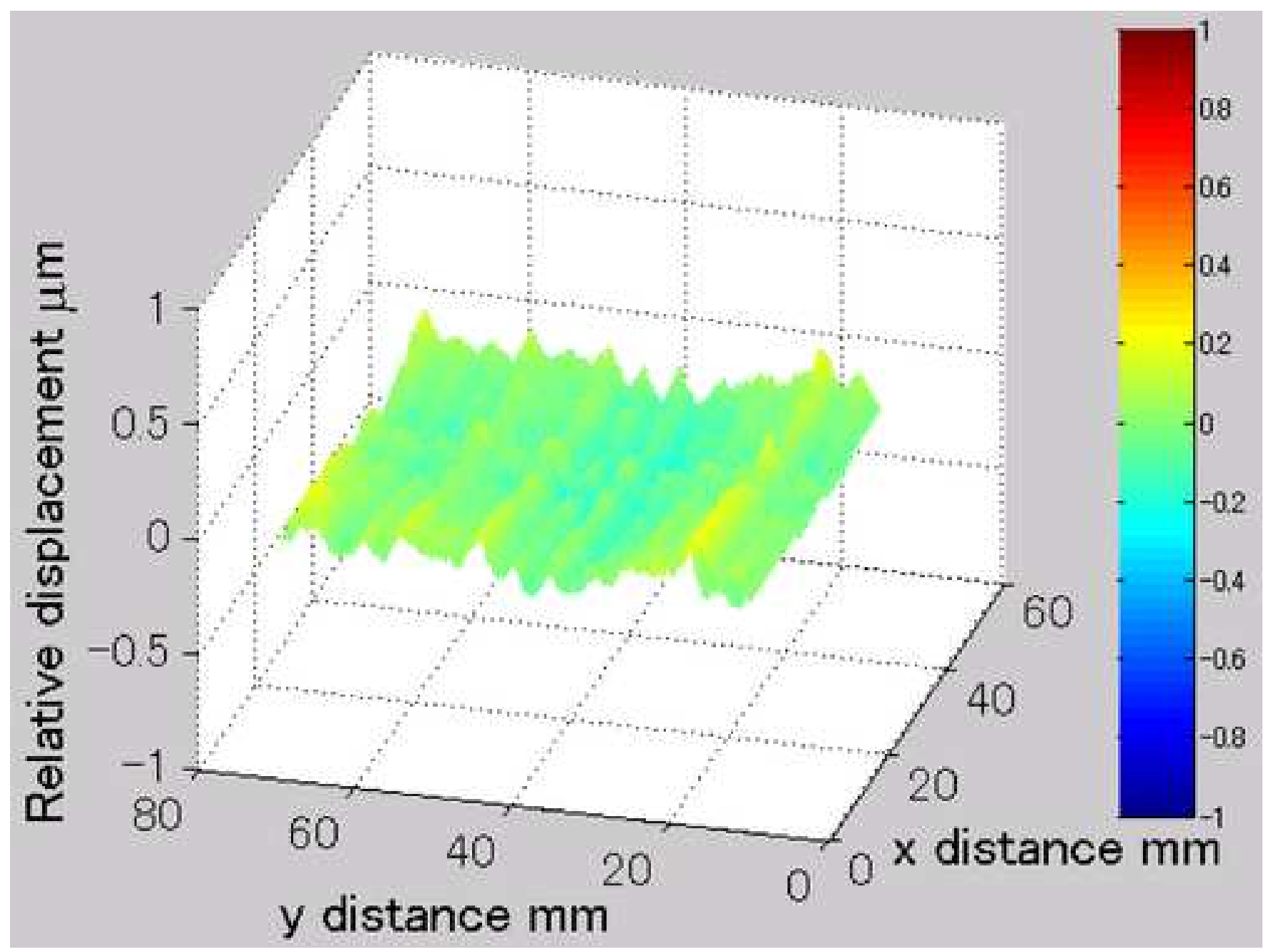




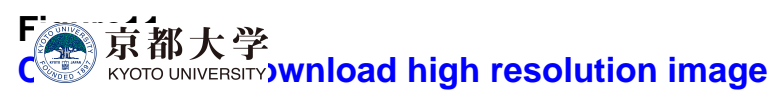

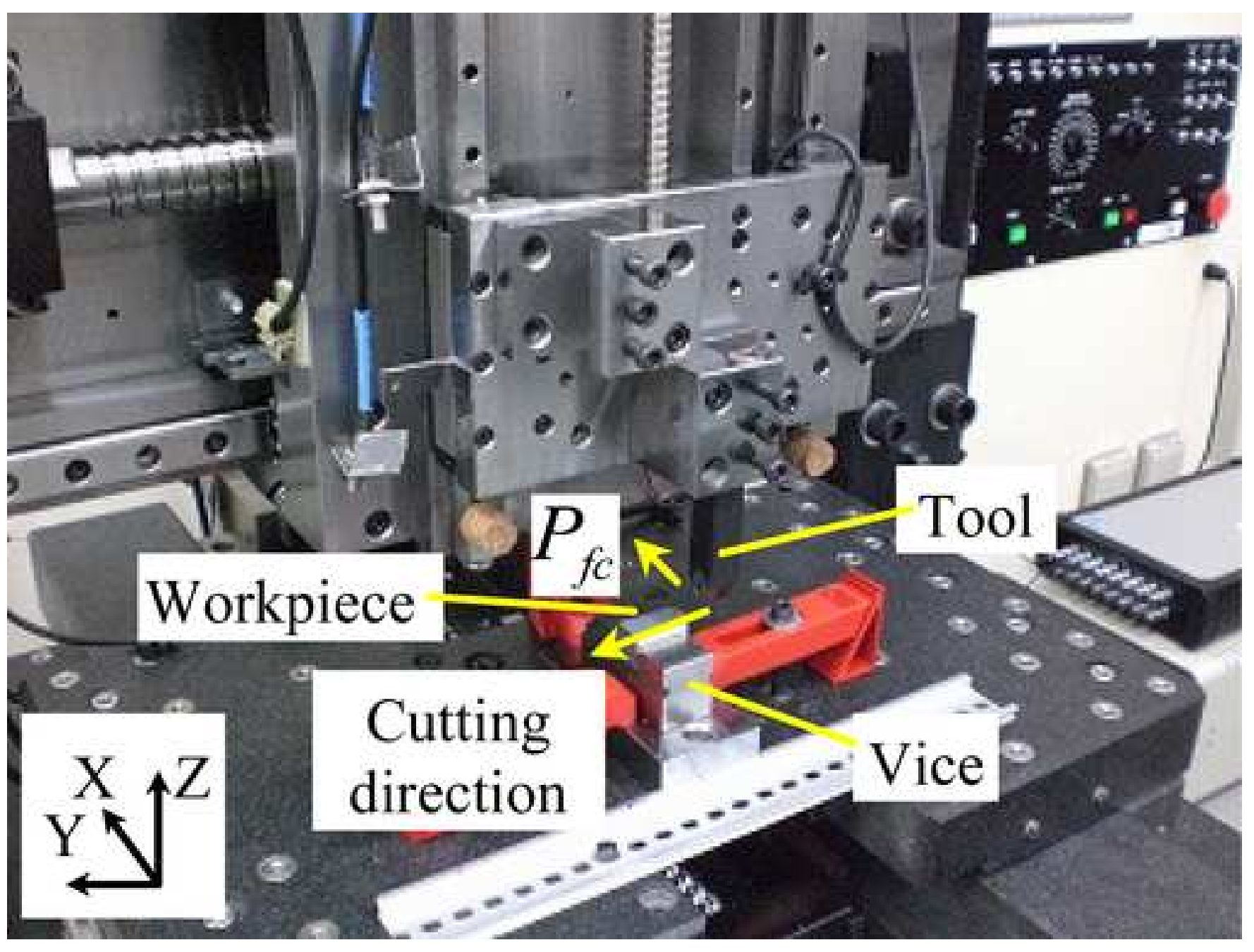

\section{Cutting}




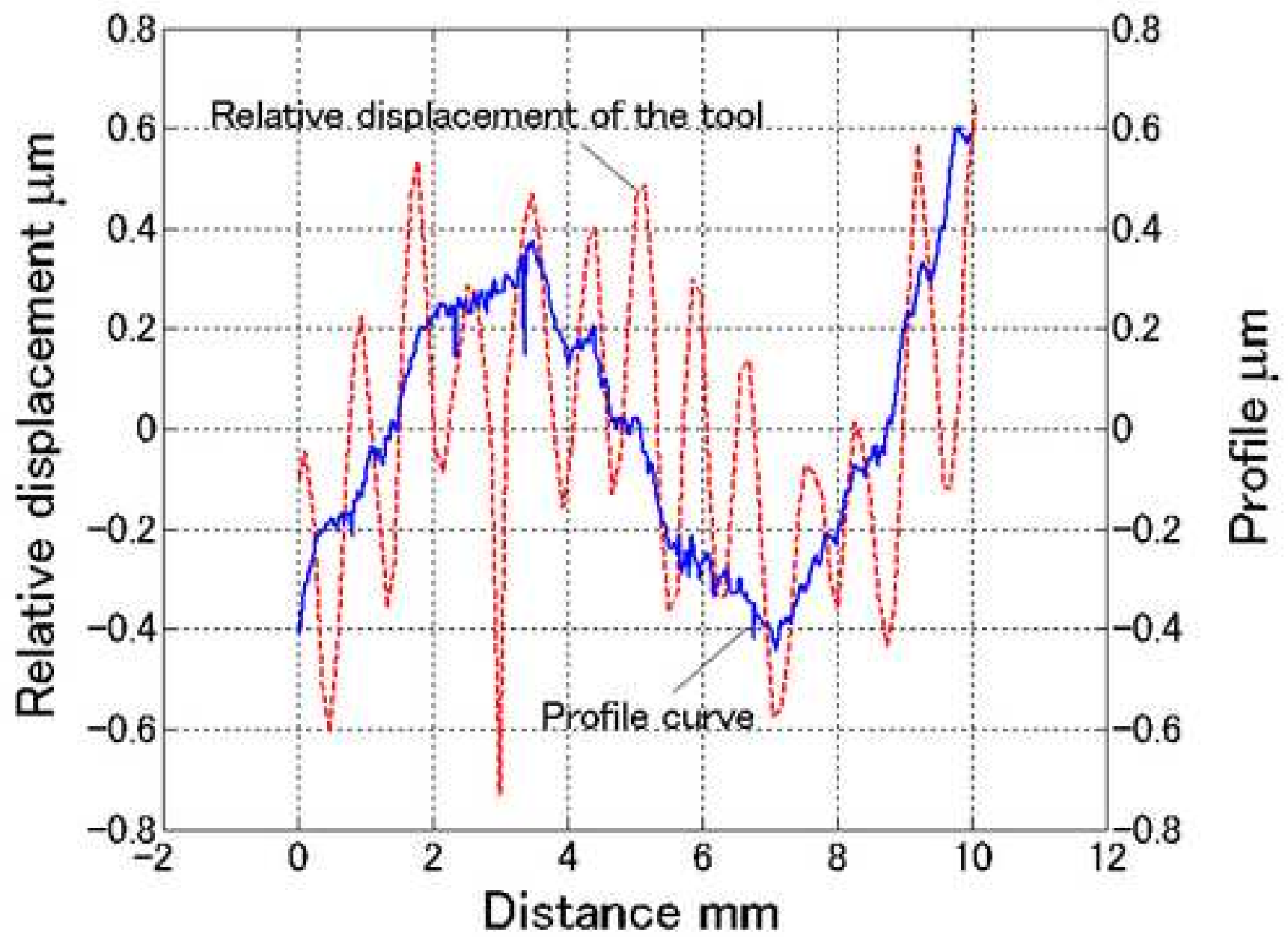




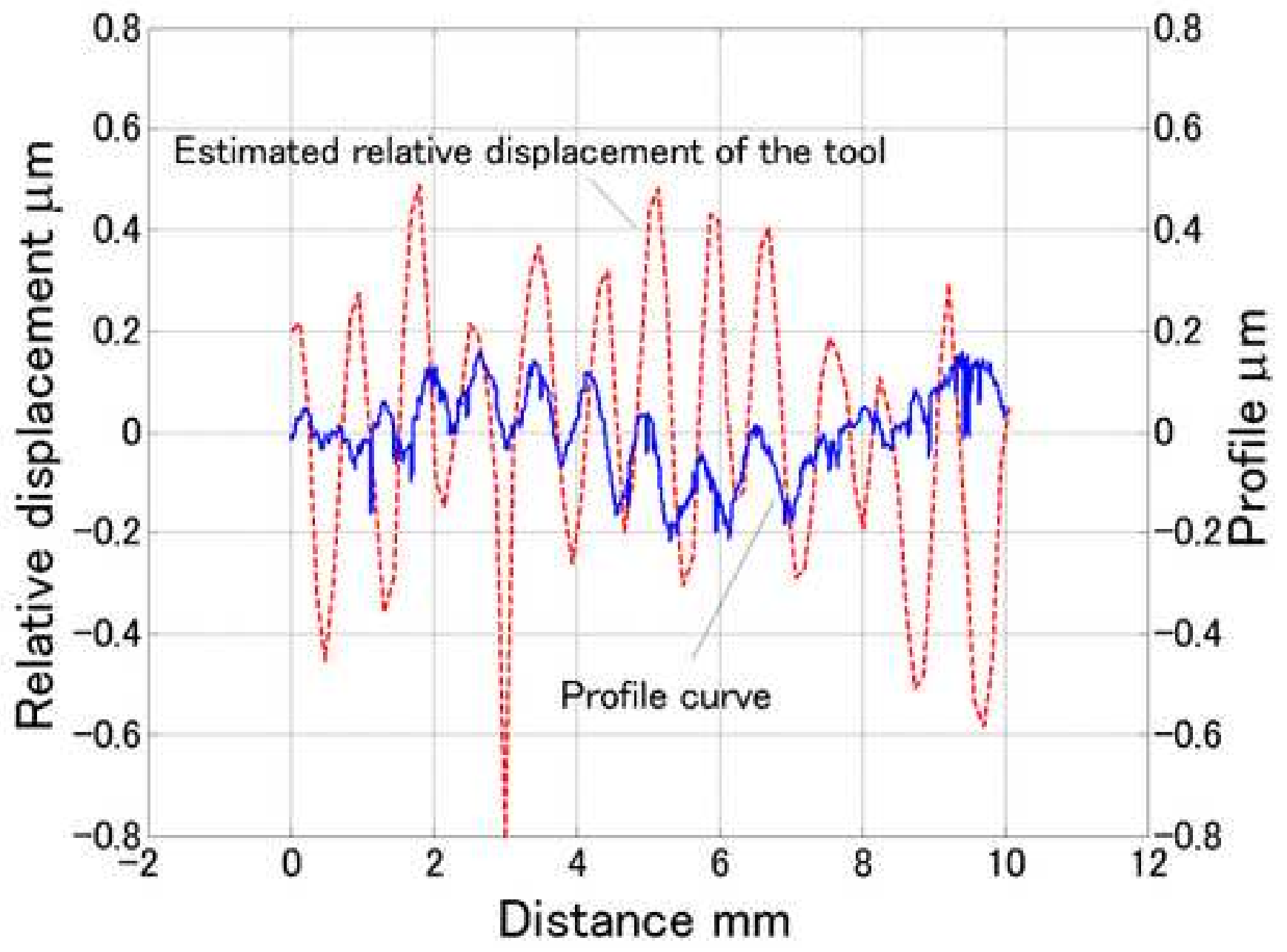


Table 1 Major specifications of the machine tool

\begin{tabular}{llll}
\hline Axis & X & Y & Z \\
Travel & $230 \mathrm{~mm}$ & $220 \mathrm{~mm}$ & $200 \mathrm{~mm}$ (Coarse) \\
& & & $5 \mu \mathrm{m}$ (Fine) \\
Maximum feedrate & $10000 \mathrm{~mm} / \mathrm{min}$ & $10000 \mathrm{~mm} / \mathrm{min}$ & $10000 \mathrm{~mm} / \mathrm{min}$ \\
Drive type & Ball screw & Ball screw & $\begin{array}{l}\text { Ball screw (Coarse)+ } \\
\text { Piezo drive (Fine) }\end{array}$ \\
Lead of ball screw & $10 \mathrm{~mm}$ & $10 \mathrm{~mm}$ & $5 \mathrm{~mm}$ \\
$\begin{array}{l}\text { Guide way } \\
\text { Control type }\end{array}$ & Aerostatic & Rolling (ball) & Rolling (ball) \\
& Full-closed & Semi-closed & Semi-closed (Coarse) \\
Resolution & $500 \mathrm{~nm}$ & & + Piezo control (Fine) \\
& \multicolumn{3}{c}{ MELDASMAGIC68 (Mitsubishi electric) } \\
\hline
\end{tabular}


Table 2 Specifications of optical flat and displacement sensor

\begin{tabular}{lll}
\hline Optical flat & Flatness & $32 \mathrm{nmP}-\mathrm{V}$ \\
& Size & \\
Displacement sensor & Sensor type & $\phi 150 \mathrm{~mm} \times 30 \mathrm{~mm}$ \\
& Resolution & Triangulation \\
& Accuracy & $10 \mathrm{~nm}$ \\
& Band width & $20 \mathrm{~nm}$ \\
& & $50 \mathrm{kHz}$ \\
\hline
\end{tabular}


Table 3 Cutting conditions

\begin{tabular}{lll}
\hline Cutting tool & $\begin{array}{l}\text { Nose radius } \\
\text { Rake angle }\end{array}$ & $10 \mathrm{~mm}$ \\
Workpiece & & $0^{\circ}$ \\
Feedrate & A2079 \\
Depth of cut & $7200 \mathrm{~mm} / \mathrm{min}$ \\
Pick feed $P_{f c}$ & $3 \mu \mathrm{m}$ \\
& & $30 \mu \mathrm{m}$ \\
\hline
\end{tabular}

